\title{
Erratum to: The social essentials of learning: an experimental investigation of collaborative problem solving and knowledge construction in mathematics classrooms in Australia and China
}

\author{
Man Ching Esther Chan ${ }^{1} \cdot$ David Clarke ${ }^{1} \cdot$ Yiming Cao $^{2}$
}

Published online: 26 July 2017

(C) Mathematics Education Research Group of Australasia, Inc. 2017

\section{Erratum to: Math Ed Res J https://doi.org/10.1007/s13394-017-0209-3}

The original version of this article unfortunately contained a mistake.

In Fig. 3, the centrally located characters " $\mathrm{C}$, c, a, m" were included in error and form no part of the intended diagram. The correct version of Fig. 3 is given below:

The original article was corrected.

\footnotetext{
The online version of the original article can be found at http://dx.doi.org/10.1007/s13394-017-0209-3
}

Man Ching Esther Chan mc.chan@unimelb.edu.au

$\triangle$ David Clarke

d.clarke@unimelb.edu.au

1 International Centre for Classroom Research, Melbourne Graduate School of Education, The University of Melbourne, Level 3, 234 Queensberry Street, Melbourne, VIC 3010, Australia

2 School of Mathematical Sciences, Beijing Normal University, Beijing 100875, China 


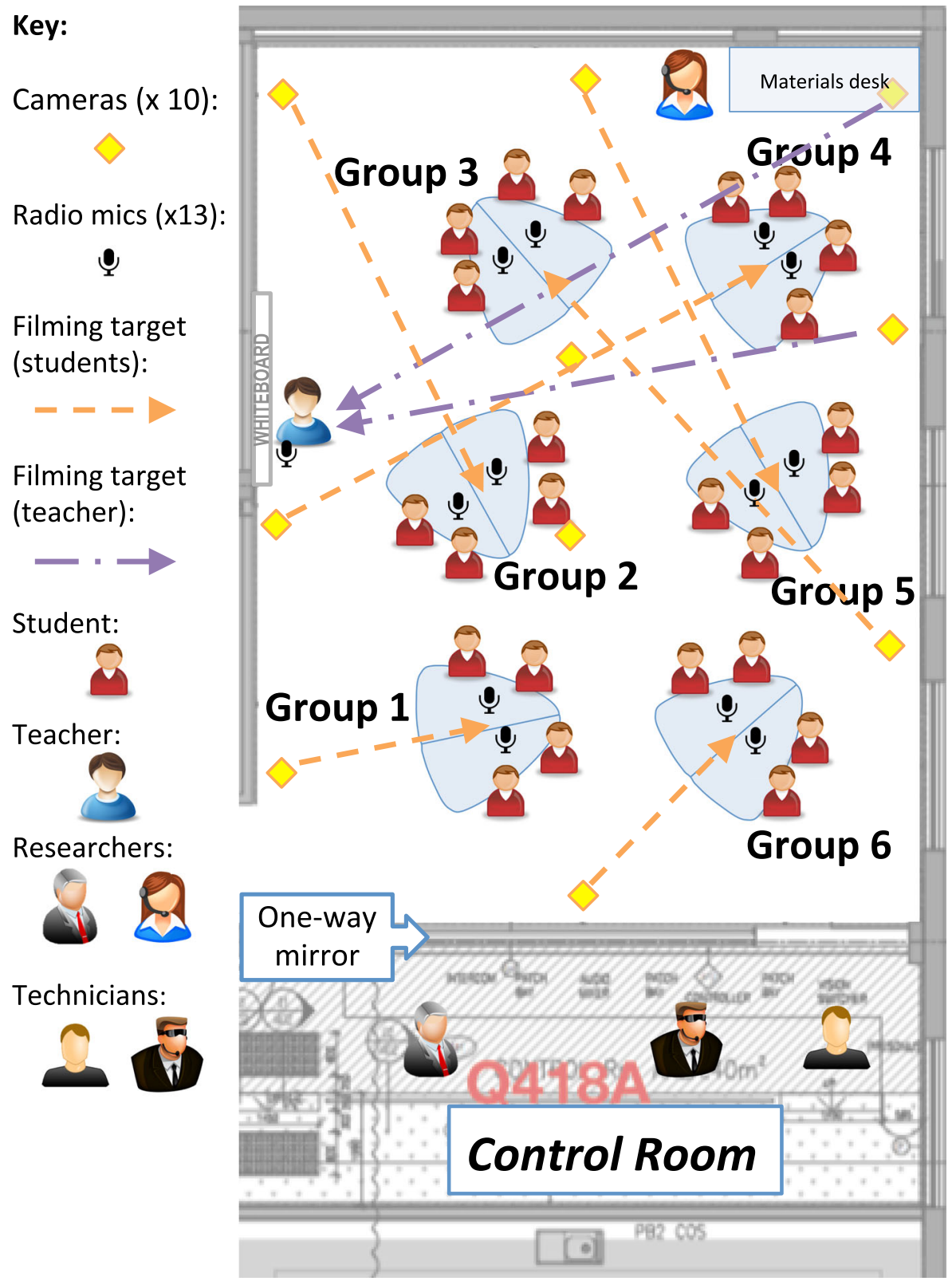

Fig. 3 Classroom configuration showing video camera sight lines 